\title{
Paleomagnetism of Volcanic Rocks from Rarotonga and Rurutu, the Cook-Austral Island Chain
}

\author{
Hayao MoRINAGA ${ }^{1}$, Satoru YAMAGUCHI ${ }^{2}$, Masayuki HyOdo ${ }^{3}$, Hiroo INOKUCHI ${ }^{4}$, \\ Nobuhiro ISEZAKI ${ }^{5}$, and Katsumi YASKAWA ${ }^{4}$ \\ ${ }^{1}$ Faculty of Science, Himeji Institute of Technology, Himeji 671-22, Japan \\ ${ }^{2}$ College of Liberal Arts, Kobe University, Nada, Kobe 657, Japan \\ ${ }^{3}$ Graduate School of Science and Technology, Kobe University, Nada, Kobe 657, Japan \\ ${ }^{4}$ Faculty of Science, Kobe University, Nada, Kobe 657, Japan \\ ${ }^{5}$ Faculty of Science, Chiba University, Yayoi 1-33, Chiba 260, Japan
}

(Received September 20, 1990; Revised August 27, 1991)

\begin{abstract}
Rarotonga $\left(21^{\circ} 15^{\prime} \mathrm{S}, 159^{\circ} 45^{\prime} \mathrm{W}\right)$ and Rurutu $\left(22^{\circ} 30^{\prime} \mathrm{S}, 151^{\circ} 20^{\prime} \mathrm{W}\right)$ are volcanic islands included in the Cook-Austral island chain. Volcanic rock samples were collected at seven and ten sites in Rarotonga and Rurutu, respectively. The mean direction of magnetization for Rarotonga is $173.8^{\circ}$ in declination and $46.2^{\circ}$ in inclination $\left(k=72.0\right.$ and $\left.\alpha_{95}=7.9^{\circ}\right)$ and is more reliable than that from a previous work. The mean direction for three young rock sites in Rurutu is $218.2^{\circ}$ in declination and $39.5^{\circ}$ in inclination $\left(k=49.3\right.$ and $\left.\alpha_{95}=17.7^{\circ}\right)$ which for five old rock sites is $188.1^{\circ}$ in declination and $51.4^{\circ}$ in inclination $\left(k=254.2\right.$ and $\alpha_{95}=$ $4.8^{\circ}$.

These paleomagnetic results are in accordance with the total intensity anomaly pattern on each island, calculated using observed values of the geomagnetic field total intensity. The implication for the formation of these two islands inferred from the present results is consistent with that inferred from $\mathrm{K}$-Ar ages and ${ }^{87} \mathrm{Sr} /{ }^{86} \mathrm{Sr}$ ratios by previous works. The formation of Rarotonga and Rurutu may be explained well by the concept of a "hot line" in a previous work rather than by the well-known "fixed hot spot" hypothesis.
\end{abstract}

\section{Introduction}

WILSON (1963) proposed that several quasi-linear chains of islands and seamounts in the Pacific Ocean extend generally in a WNW-ESE direction and tend to be younger at the ESE end. $\mathrm{He}$ also suggested that these chains were formed by relative motion between the lithosphere and a "hot spot" in the mantle. MORGAN (1972) offered the hypothesis that the "hot spots" were fixed, both relative to one another and the earth's spin axis, and that they were the surface expression of deep mantle plumes extending to the lowest part of the mantle.

Available age data from the Hawaiian, Marquesas, Kodiak-Bowie, Society, Caroline and Guadalupe chains, all WNW trending Pacific chains, follow patterns of generally increasing ages to the WNW (JARRARD and CLAGUE, 1977). The rates of volcanic propagation for these chains inferred from the age data are not significantly different from each other, strongly supporting the "fixed hot spot" hypothesis. Age data from the Cook-Austral chain, however, follow no simple pattern; ages are younger (Rarotonga, Aitutaki and Rurutu) and older 
(Tubuai and Raevavae) than would be expected from the hypothesis that a "hot spot" is located at MacDonald Seamount (DALRYMPLE et al., 1975). In order to account for this discrepancy, TURNER and JARRARD (1982) proposed the possibility that the Cook-Austral chain originated from several "hot spots" (at least three), which must be successively turned on and off very fast (in less than a few m.y.) to explain the absence of present-day activity, except at the ESE end of the chain at MacDonald Seamount. They also applied the concept of a "hot line" (BONATTI and HARRISON, 1976) to the portion of Quaternary volcanism in the Cook-Austral chain at Rarotonga, Aitutaki, Rurutu and MacDonald Seamount.

Rarotonga and Rurutu are situated at $21^{\circ} 15^{\prime} \mathrm{S}, 159^{\circ} 45^{\prime} \mathrm{W}$ and $22^{\circ} 30^{\prime} \mathrm{S}, 151^{\circ} 20^{\prime} \mathrm{W}$ in the Cook and Austral Islands, respectively (Fig. 1). Volcanic rocks from Rarotonga show younger ages of 1.1 to $2.3 \mathrm{~m} . y$. ., than what is expected from the "fixed hot spot" hypothesis (DALRYMPLE et al., 1975; TURNER and JARRARD, 1982; MATSUDA et al., 1984). For volcanic rocks from Rurutu, at least two groups of ages of about 1 m.y. and about 11 m.y. have been reported (DALRYMPLE et al., 1975; DUNCAN and MCDOUGALL, 1976; TURNER and JARRARD, 1982; MATSUDA et al., 1984). This suggests that volcanism on Rurutu evidently started about $11 \mathrm{~m} . \mathrm{y}$. ago and that new activity commenced after a hiatus of about $10 \mathrm{~m} . \mathrm{y}$. The ${ }^{87} \mathrm{Sr} /{ }^{86} \mathrm{Sr}$ ratios are different between Rarotonga and Rurutu (MATSUDA et al., 1984). For Rurutu, the ratios obtained from both young (about 1 m.y.) and old (about 11 m.y.) rocks were identical within the range of $0.7026-0.7035$, which is thought to be of the magma source characteristic of the Cook-Austral islands "hot spot" (DUNCAN and COMPSTON, 1976). For Rarotonga, however, the ratios were identical within the range of $0.7041-0.7045$, suggesting the possibility that Rarotonga did not originate from the single "hot spot" responsible for the Cook-Austral islands chain (MATSUDA et al., 1984).

The aims of this, work and some others works like, a previous one for Hiva-Oa in the Marquesas islands (KATAO et al., 1988), and works in progress for islands in the Society and Marquesas islands, are not only to test the "fixed hot spot" hypothesis for several volcanic

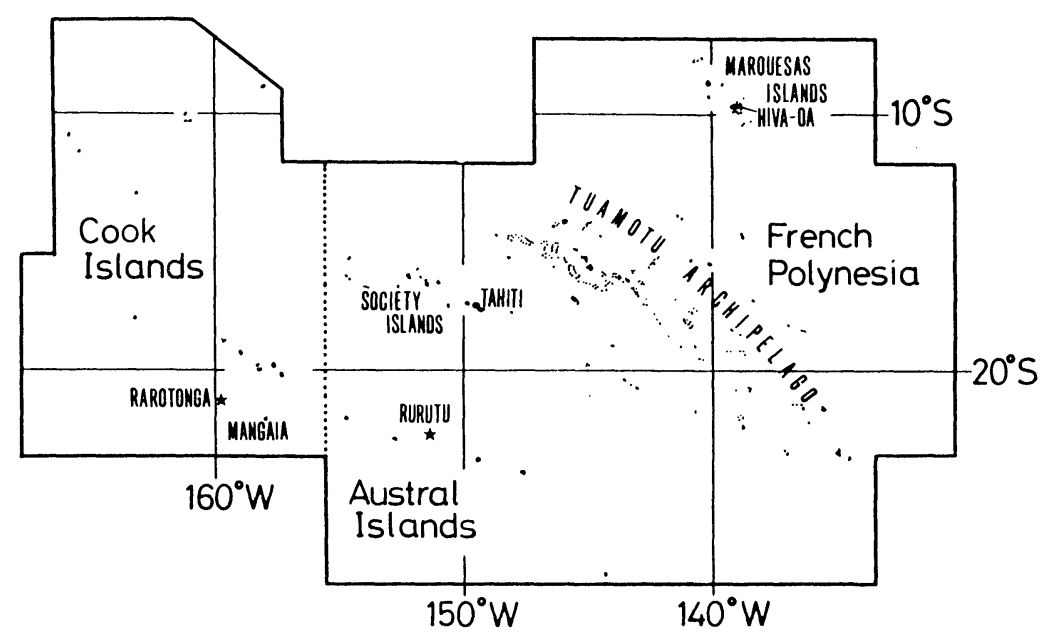

Fig. 1. Location of Rarotonga and Rurutu in the Cook and Austral Islands. 
chains but also to estimate the paleo-secular variation (PSV) of the ancient geomagnetic field in the Southeast Pacific region, through the paleomagnetic investigations. In particular, the present paper presents the paleomagnetic results of volcanic rocks collected from Rarotonga and Rurutu.

\section{Sampling and Magnetic Measurement}

Rarotonga and Rurutu are included in the Cook-Austral island chain in the South Pacific, between Tahiti and Fiji (Fig. 1). Rarotonga is geomorphically the youngest of the Cook Islands and is composed of a single volcanic shield with large caldera, and with rugged and mountainous terrain rising to $650 \mathrm{~m}$ in elevation (TURNER and JARRARD, 1982). Rurutu, in the Austral Islands about $200 \mathrm{~km}$ east of the east end of the chain, is a deeply dissected shield volcano rising to $400 \mathrm{~m}$ in elevation (TURNER and JARRARD, 1982).

In 1979, we collected volcanic rock (alkalic rock series) samples from seven sites (named A to $\mathrm{G}$ ) for Rarotonga and ten sites (named A to H, J and K) for Rurutu (Fig. 2). Numerals adjacent to several sampling sites in Fig. 2 indicate the K-Ar ages determined by MATSUDA et al. (1984) from rock samples collected from the same site. Four of seven sites in Rarotonga were from Tuoro quarry (A and G) and Avatiu Valley (B and C) where TARLING (1967) had already collected rock samples for a paleomagnetic investigation. Hand rock samples were taken and a magnetic compass was used for orientation. Each site is comprised of two to five independently oriented samples.

In the laboratory, individual subsamples of $25 \mathrm{~mm}$ in diameter and $25 \mathrm{~mm}$ in length were cored from the hand samples. All magnetic measurements were made with a spinner magnetometer. At each site, several pilot subsamples (all in A- and G-sites) were subjected to progressive alternating field demagnetization (PAFD), which was carried out with a three-axis

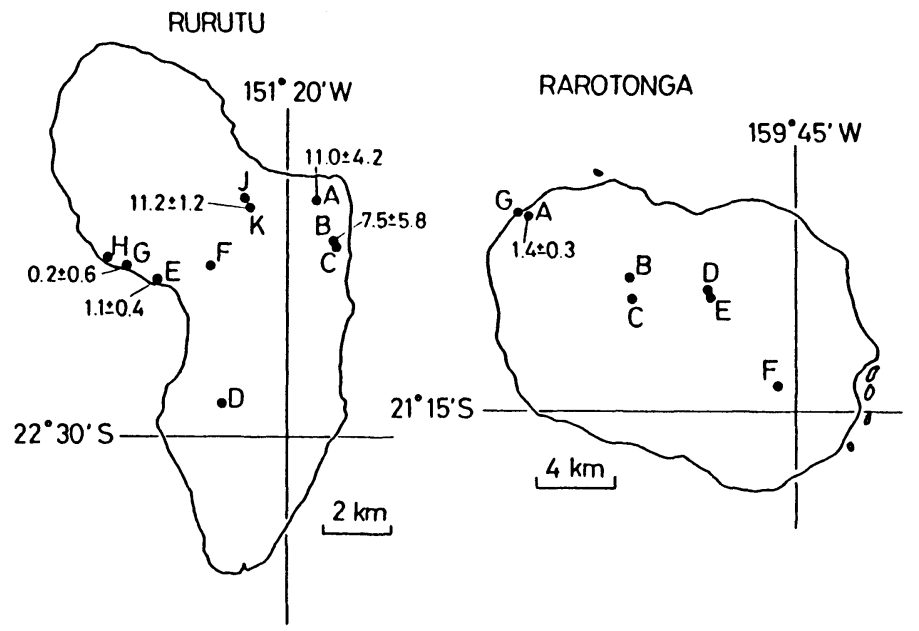

Fig. 2. Sampling sites in Rarotonga (right) and Rurutu (left). Numerals adjacent to several sites show K-Ar ages in m.y. determined by MATSUDA et al. (1984). 

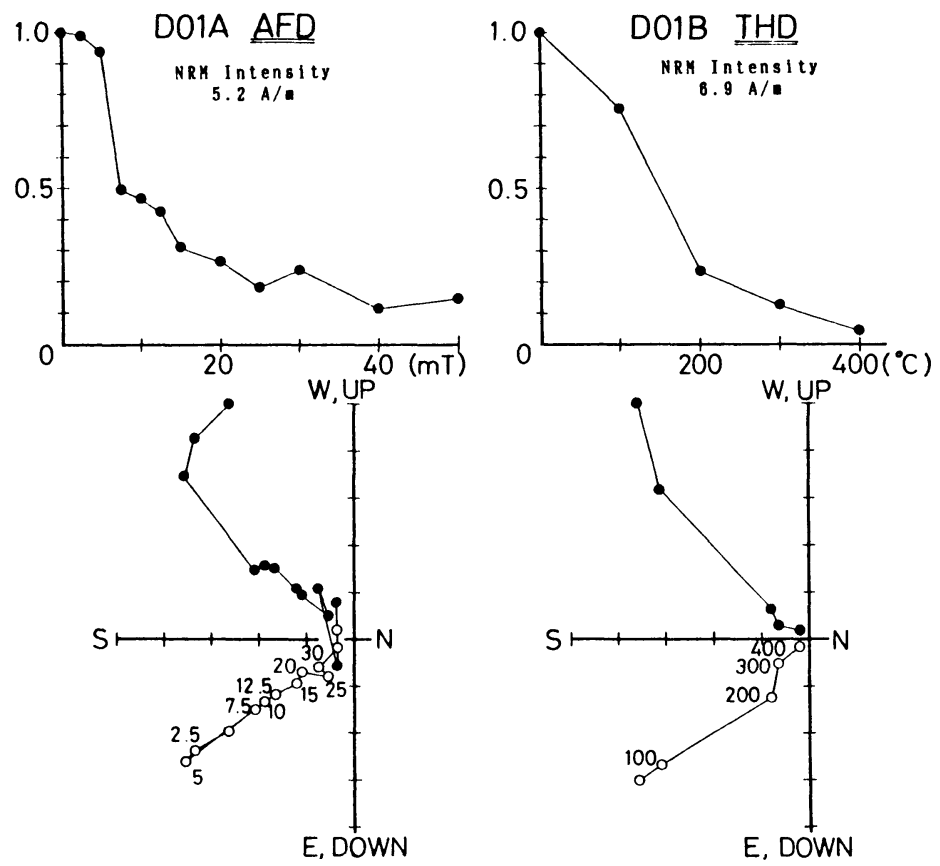

Fig. 3. Orthogonal projections of magnetization vector end points (lower) and intensity decay curves (upper) during progressive alternating field (left) and thermal (right) demagnetization treatments for pilot subsamples at a site D from Rurutu. Open (solid) symbols on the orthogonal projection show the magnetic vectors projected onto the vertical (horizontal) plane. Numbers adjacent to symbols represent the $A F$ intensity (mT) or temperature $\left({ }^{\circ} \mathrm{C}\right)$.

tumbler system in single-fold cylindrical $\mu$-metal shield. At each site from Rurutu, only one subsample was subjected to progressive thermal demagnetization (PTD). Preliminary PTD experiments for pilot subsamples indicated that natural remanent magnetizations were unstable to thermal treatment and their intensity decayed quickly up to $200-300^{\circ} \mathrm{C}$, showing only one magnetic component (Fig. 3). It is possible to separate the median temperature $\left(300-400^{\circ} \mathrm{C}\right)$ component by the PTD with closer steps. However, our thermal demagnetizer used then did not have the thermal controller with high reliability. Finally, the PTD experiments was not as effective as the PAFD method, in erasing a secondary viscous magnetization and separating stable magnetic signals by the principal component analysis (PCA) (Fig. 3).

\section{Determination of the Characteristic Direction for Each Site}

\subsection{Rarotonga}

A-site

All 13 subsamples cored from 5 collected samples were progressively cleaned at the $A F$ levels of $2.5,5,7.5,10,15,20,30,40$, and $50 \mathrm{mT}$. All the subsamples have both lower and 
higher coercivity components separated at the $A F$ level of $15 \mathrm{mT}$ (Fig. 4-A01B). The directions of lower coercivity components for all the subsamples, which were obtained by the PCA of KIRSCHVINK (1980), show the mean of $237.2^{\circ}$ in declination and $57.7^{\circ}$ in inclination $\left(k=3.8\right.$ and $\alpha_{95}=25.9^{\circ}$ ). The directions of higher coercivity components (the PCA ranges are from about $20 \mathrm{mT}$ to the origin) obtained through the same process show the mean of $157.3^{\circ}$ in declination and $48.0^{\circ}$ in inclination $\left(k=13.4\right.$ and $\left.\alpha_{95}=11.7^{\circ}\right)$. The directions of the higher coercivity components are highly concentrated in contrast to those of the lower coercivity components which are most likely a viscous remanent magnetization (VRM). Therefore, the mean of the higher coercivity component's directions obtained by the PCA is adopted as the characteristic direction for this site (Fig. 5-A and Table 1).

At the $20 \mathrm{mT}$ level, a higher coercivity component was detected. Thus, this level gives the optimum demagnetizing field (ODF). The mean direction of the residual magnetization at this level after the AFD treatment is $157.1^{\circ}$ in declination and $49.6^{\circ}$ in inclination $(k=15.0$ and $\alpha_{95}=11.1^{\circ}$ ) for all the subsamples, being in considerably good agreement with the mean direction of the high coercivity component obtained by the PCA (the angular difference is $1.6^{\circ}$ as a solid angle). Therefore, at the other sites from Rarotonga and all the sites from Rurutu, we selected two to four pilot subsamples and cleaned them through the PAFD treatment. Then we determined the characteristic directions for each site, comparing the mean direction of the component obtained by the PCA with that of the residual magnetization after the AFD treatment at the ODF level for the pilot subsamples.

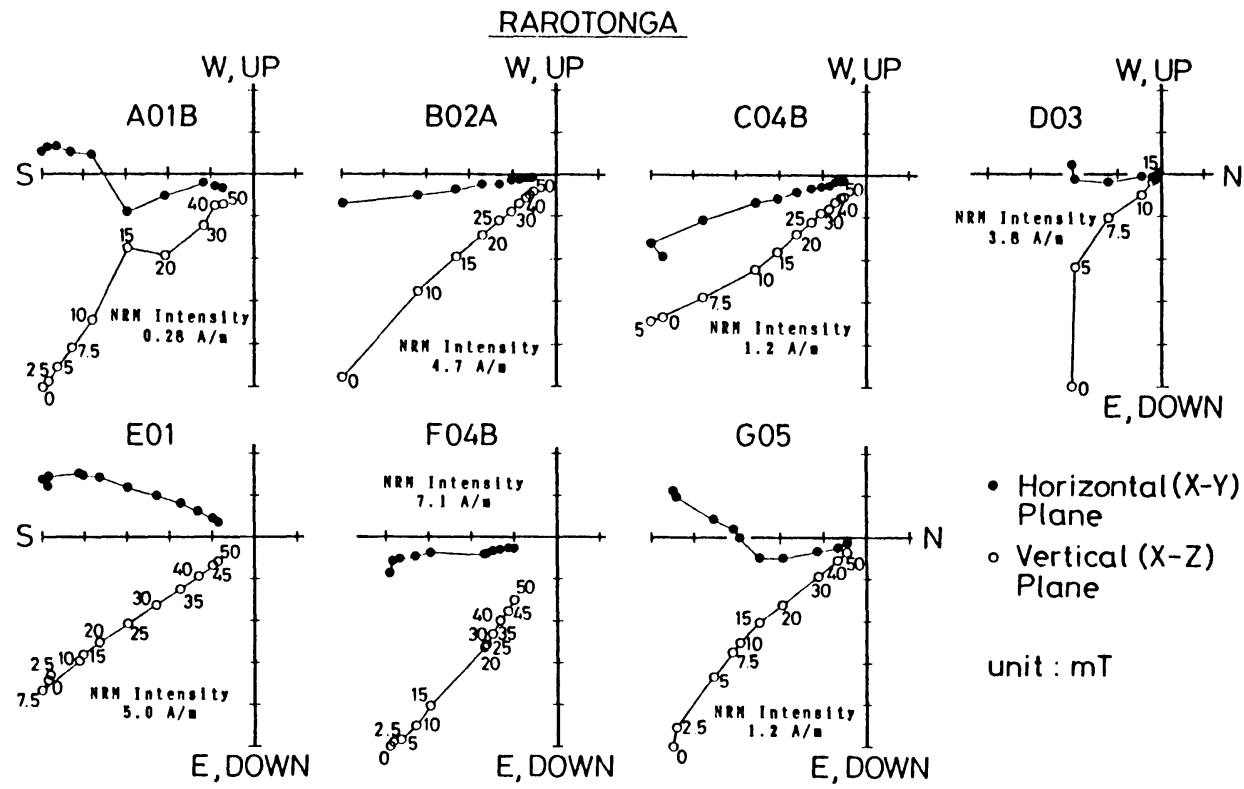

Fig. 4. Orthogonal projections of magnetization vector end points during progressive alternating field demagnetization treatments for pilot subsamples at every site from Rarotonga. Open (solid) symbols show the magnetic vectors projected onto the vertical (horizontal) plane. Numbers adjacent to symbols represent the $A F$ intensity (mT). 


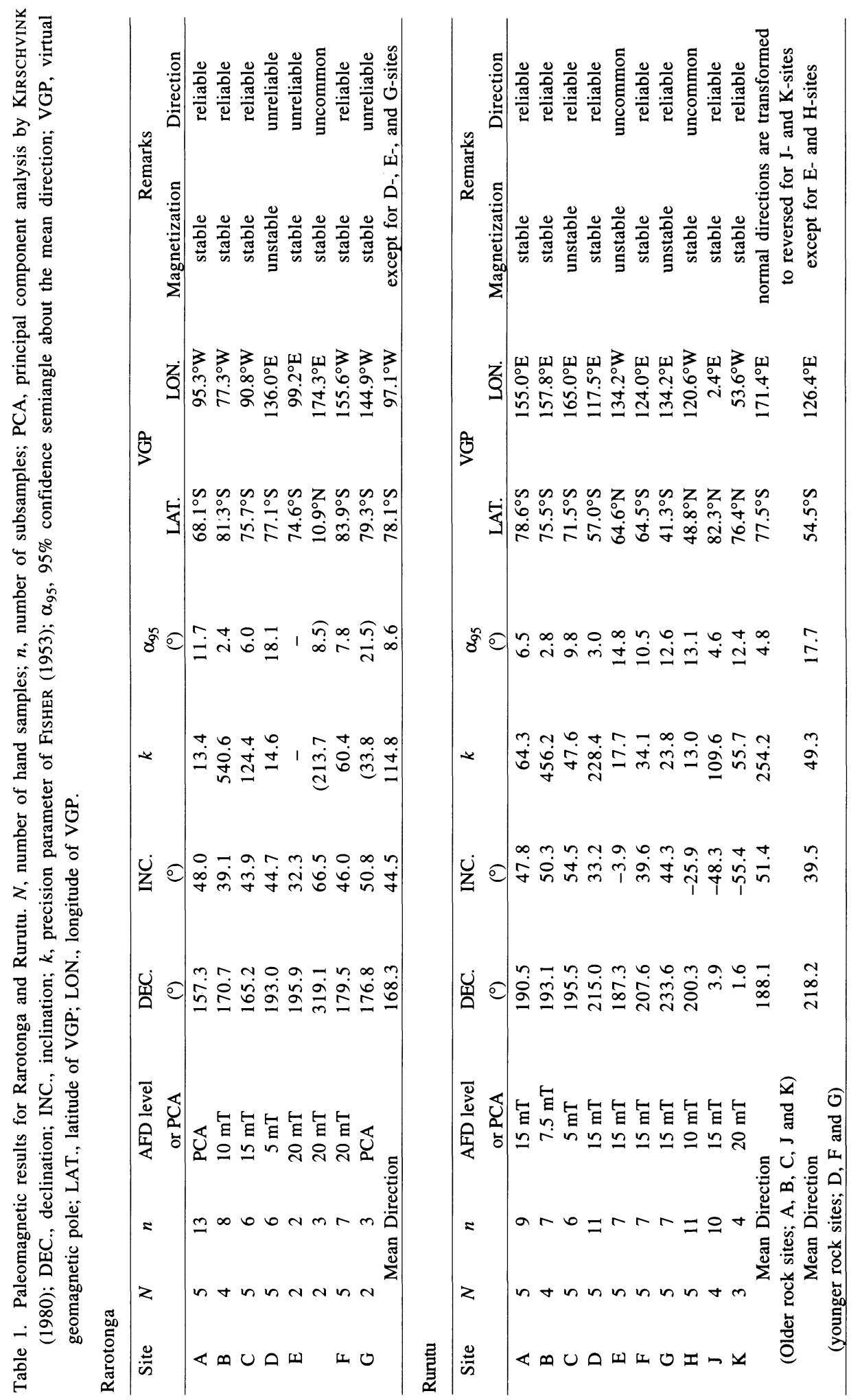




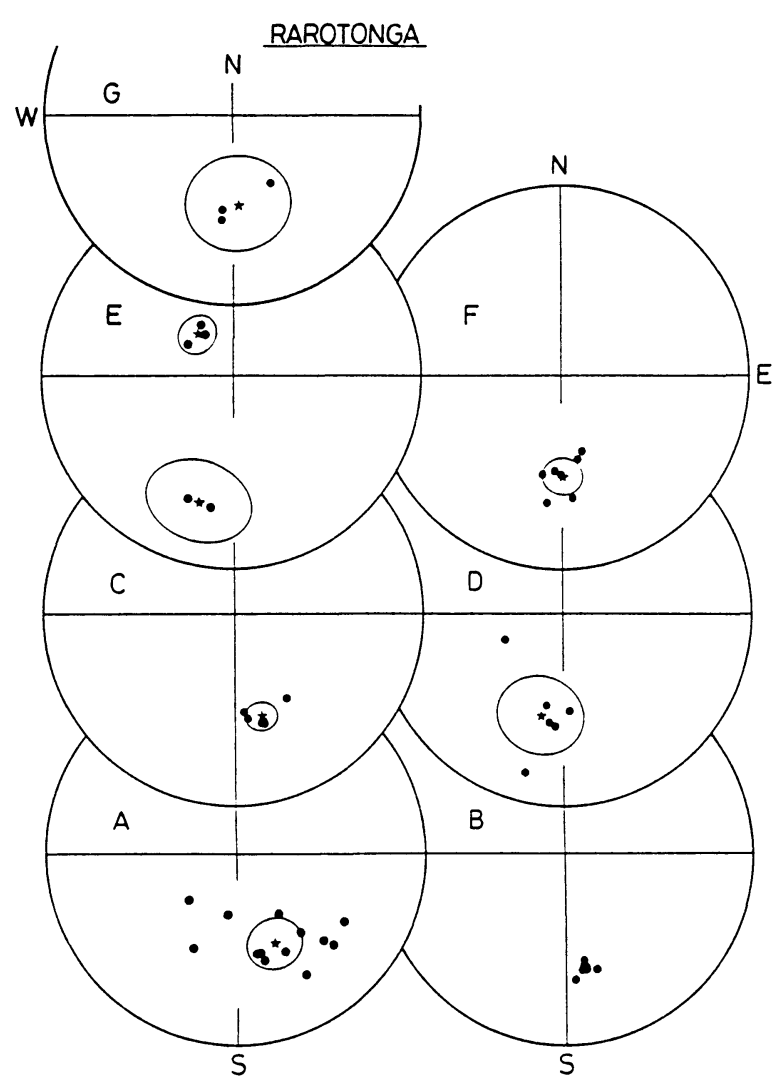

Fig. 5. Directions of magnetization for all demagnetized subsamples of volcanic rocks at every site from Rarotonga. The mean direction for each site is indicated by a star with its $95 \%$ confidence intervals.

\section{$B$-site}

Two pilot subsamples were progressively cleaned at the $A F$ levels of $10,15,20,25,30$, $35,40,45$, and $50 \mathrm{mT}$. Only one stable component, which has a demagnetization trajectory that converged toward the origin, was recognized (Fig. 4-B02A). The mean direction of the component obtained by the PCA (the range is from $10 \mathrm{mT}$ to the origin) is $173.5^{\circ}$ in declination and $37.1^{\circ}$ in inclination for the two pilot subsamples. The mean direction of the stable component after the AFD treatment at the $10 \mathrm{mT}$ (ODF) level, is $173.3^{\circ}$ in declination and $37.3^{\circ}$ in inclination and agrees well with the mean obtained by the PCA (the angular difference is $0.3^{\circ}$ ). On the basis of this good agreement, the rest of the subsamples were cleaned in the ODF at $10 \mathrm{mT}$. The mean direction of the residual magnetization after the ODF demagnetization is $170.7^{\circ}$ in declination and $39.1^{\circ}$ in inclination $\left(k=540.6\right.$ and $\left.\alpha_{95}=2.4^{\circ}\right)$ for all six subsamples (Fig. 5-B and Table 1) and is adopted as the characteristic direction for this site. 
C-site

Two pilot subsamples were progressively cleaned at the $A F$ levels of $5,7.5,10,15,20$, $25,30,35,40,45$, and $50 \mathrm{mT}$. Only one stable component, which has a demagnetization trajectory that converged toward the origin, is recognized after eliminating a scanty VRM at the $10 \mathrm{mT}$ level (Fig. 4-C04B). The mean direction of the component obtained by the PCA (the range is from 5 or $7.5 \mathrm{mT}$ to the origin) is $167.1^{\circ}$ in declination and $39.9^{\circ}$ in inclination for the two pilot subsamples. The mean direction of the stable component after the AFD treatment at $15 \mathrm{mT}$ (ODF) level is $168.5^{\circ}$ in declination and $42.3^{\circ}$ in inclination, being in good agreement with the mean obtained by the PCA (the angular difference is $2.6^{\circ}$ ). On the basis of this agreement, the rest of the subsamples were cleaned at the ODF of $15 \mathrm{mT}$. The mean direction of the residual magnetization after the ODF demagnetization is $165.2^{\circ}$ in declination and $43.9^{\circ}$ in inclination $\left(k=124.4\right.$ and $\alpha_{95}=6.0^{\circ}$ ) for all six subsamples (Fig. 5$\mathrm{C}$ and Table 1) and is adopted as the characteristic direction for this site.

D-site

Two pilot subsamples were progressively cleaned at the $A F$ levels of $5,7.5,10,15,20$, $25,30,35,40,45$, and $50 \mathrm{mT}$. The natural remanent magnetization (NRM) of the rock samples from this site is the most unstable in Rarotonga. Although a VRM is eliminated at the $5 \mathrm{mT}$ level, the remanent magnetization is not highly stable against the AFD above that level (Fig. 4-D03). The mean direction of the component obtained by the PCA (the range is from $5 \mathrm{mT}$ to $25 \mathrm{mT}$ ) is $186.7^{\circ}$ in declination and $32.1^{\circ}$ in inclination for the two pilot subsamples. The mean direction of the component after the AFD treatment at the $5 \mathrm{mT}$ level, is $186.9^{\circ}$ in declination and $32.1^{\circ}$ in inclination. The mean directions obtained through both processes are highly dispersed but still agree well with each other (the angular difference is $0.2^{\circ}$ ). The mean direction of the residual magnetization after the AFD treatment of the $5 \mathrm{mT}$ level is $193.0^{\circ}$ in declination and $44.7^{\circ}$ in inclination $\left(k=14.6\right.$ and $\left.\alpha_{95}=18.1^{\circ}\right)$ for all six subsamples (Fig. 5-D and Table 1) and is not so concentrated (the $\alpha_{95}$ is very large). Therefore, it is adopted as an estimated value of the characteristic direction for this site.

\section{E-site}

The NRM directions of four collected samples (E01, E02, E04 and E05) are divided into two groups. One group (E01 and E04) shows the reversed direction, and the other (E02 and E05) shows an ambiguous direction, which is neither normal nor reversed. Each pilot subsample from the two groups was progressively cleaned at the $A F$ levels of $2.5,7.5,10$, $15,20,25,30,35,40,45$, and $50 \mathrm{mT}$. Each remanent magnetization of the two pilot subsamples behaves in the same manner to each other and each one stable component is recognized after the AFD treatment above $15 \mathrm{mT}$ level (Fig. 4-E01). Since the direction of the component obtained by the PCA (the range is from $10 \mathrm{mT}$ to the origin for the former group or $30 \mathrm{mT}$ for the latter group) agreed well with that of the residual magnetization, after the AFD at the $20 \mathrm{mT}$ level for each pilot subsample, the rest of the subsamples were cleaned at the $A F$ level of $20 \mathrm{mT}$. The mean direction for the two subsamples showing the reversed directions is $195.9^{\circ}$ in declination and $32.3^{\circ}$ in inclination (Fig. 5-E and Table 1). On the other hand, the mean direction of the three subsamples showing ambiguous directions is $319.1^{\circ}$ in declination and $66.5^{\circ}$ in inclination (Fig. 5-E and Table 1). The former mean direction is adopted as the characteristic direction for this site, because the latter cannot be recognized in all samples from the other site, and is questionable.

F-site

Two pilot subsamples were progressively cleaned at the $A F$ levels of $2.5,5,10,15,20$, $25,30,35,40,45$, and $50 \mathrm{mT}$. Two pilot subsamples have both lower coercivity and higher 
coercivity components clearly identified at the $A F$ level of $20 \mathrm{mT}$. The directions of these two components are the same (Fig. 4-F04B). The mean direction of the components obtained by the PCA (the range is from $0 \mathrm{mT}$ to the origin) is $175.4^{\circ}$ in declination and $49.8^{\circ}$ in inclination for the two pilot subsamples. The mean direction of the residual magnetization after the AFD treatment at the $20 \mathrm{mT}$ (ODF) level is $173.9^{\circ}$ in declination and $51.8^{\circ}$ in inclination and agrees well with the mean obtained by the PCA (the angular difference is $2.2^{\circ}$ ). On the basis of this agreement, the rest of the subsamples were cleaned at the ODF of $20 \mathrm{mT}$. The mean direction of the residual magnetization after the ODF demagnetization is $179.5^{\circ}$ in declination and $46.0^{\circ}$ in inclination $\left(k=60.4\right.$ and $\left.\alpha_{95}=7.8^{\circ}\right)$ for all seven subsamples (Fig. 5-F and Table 1) and is adopted as the characteristic direction for this site.

$G$-site

Three subsamples cored from the two rock samples used for magnetic measurement were progressively cleaned at the $A F$ levels of $2.5,5,7.5,10,15,20,30,40$, and $50 \mathrm{mT}$. The results show that the subsamples have both lower and higher coercivity components separated at the $A F$ level of $15 \mathrm{mT}$ (Fig. 4-G05). The mean direction of the higher coercivity component obtained by the PCA (the range is from $15 \mathrm{mT}$ to $30 \mathrm{mT}$ or the origin) is $176.8^{\circ}$ in declination and $50.8^{\circ}$ in inclination $\left(k=33.8\right.$ and $\left.\alpha_{95}=21.5^{\circ}\right)$ for the three subsamples (Fig. 5-G and Table 1). This mean is not highly reliable (the $\alpha_{95}$ is very large) but is adopted as the characteristic direction for this site.

\subsection{Rurutu}

A-site

Three pilot subsamples were progressively cleaned at the $A F$ levels of $5,7.5,10,12.5$, $15,20,25,30,40$, and $50 \mathrm{mT}$. The results show that the subsamples have both lower and higher coercivity components clearly separated at the $A F$ level of $15 \mathrm{mT}$ (Fig. 6-A05). The mean direction of the higher coercivity component obtained by the PCA (the range is from 0 , 12.5 or $15 \mathrm{mT}$ to the origin) is $185.2^{\circ}$ in declination and $57.9^{\circ}$ in inclination for the three pilot subsamples. The mean direction of the residual magnetization after the AFD treatment at the $15 \mathrm{mT}$ (ODF) level is $184.2^{\circ}$ in declination and $55.1^{\circ}$ in inclination, being in good agreement with the mean obtained by the PCA (the angular difference is $2.9^{\circ}$ ). On the basis of this agreement, the rest of the subsamples were cleaned at the ODF of $15 \mathrm{mT}$. The mean direction of the residual magnetization after the ODF demagnetization is $190.5^{\circ}$ in declination and $47.8^{\circ}$ in inclination $\left(k=64.3\right.$ and $\left.\alpha_{95}=6.5^{\circ}\right)$ for all nine subsamples (Fig. 7-A and Table 1$)$ and is adopted as the characteristic direction for this site.

$B$-site

Three pilot subsamples were progressively cleaned at the $A F$ levels of $5,7.5,10,12.5$, $15,20,25,30,40$, and $50 \mathrm{mT}$. Only one stable component, which has a demagnetization trajectory that converged toward the origin, is recognized after eliminating a scanty VRM at the $A F$ level of $7.5 \mathrm{mT}$ (Fig. 6-B01). The mean direction of the component obtained by the PCA (the range is from 0 or $5 \mathrm{mT}$ to the origin) is $197.0^{\circ}$ in declination and $54.3^{\circ}$ in inclination for the three pilot subsamples. The mean direction of the stable residual magnetization after the AFD treatment at the $7.5 \mathrm{mT}$ (ODF) level, is $196.8^{\circ}$ in declination and $51.3^{\circ}$ in inclination, being in good agreement with the mean obtained by the PCA (the angular difference is $3.0^{\circ}$ ). On the basis of this agreement, the rest of the subsamples were cleaned at the ODF of $7.5 \mathrm{mT}$. The mean direction of the residual magnetization after the ODF demagnetization is $193.1^{\circ}$ in declination and $50.3^{\circ}$ in inclination $\left(k=456.2\right.$ and $\alpha_{95}=$ $2.8^{\circ}$ ) for all seven subsamples (Fig. 7-B and Table 1) and is of high reliability (the $\alpha_{95}$ is 


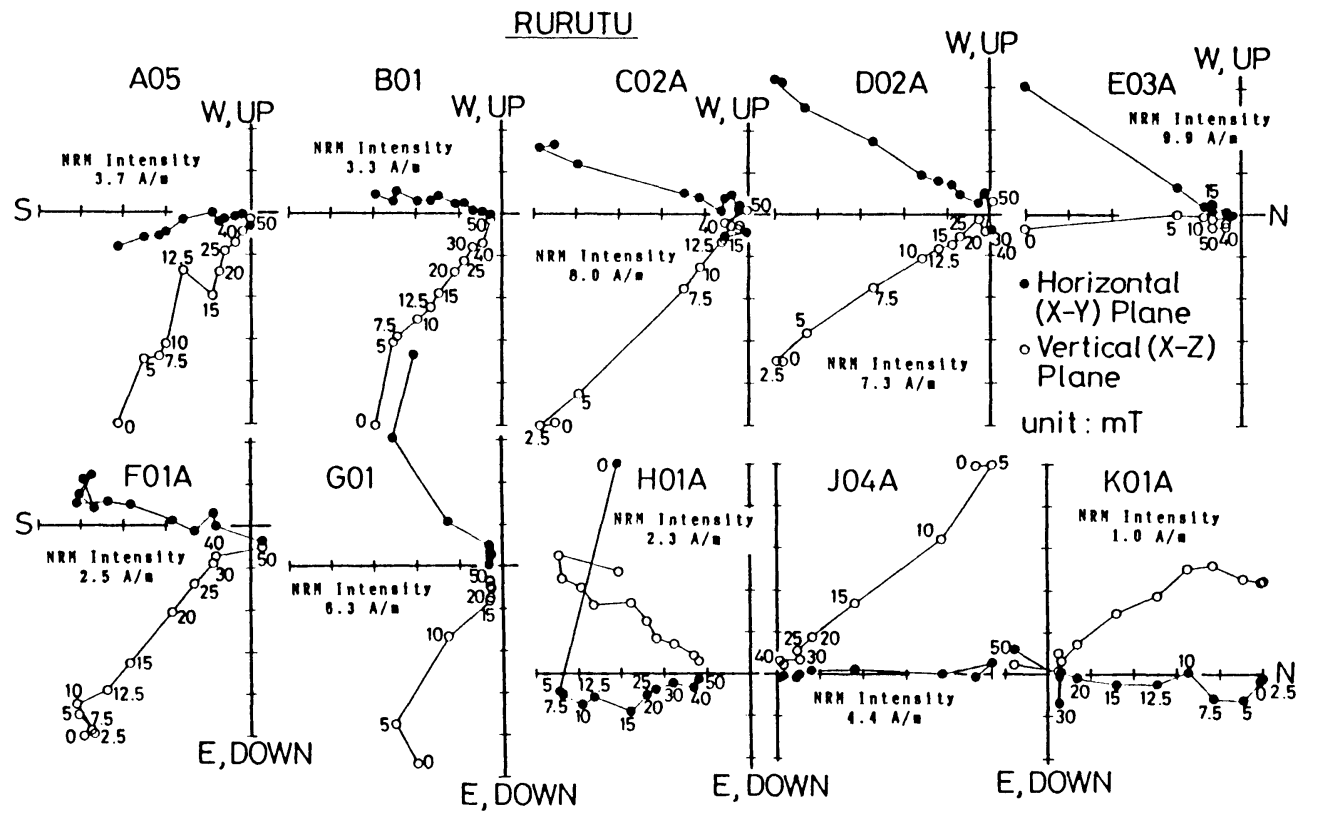

Fig. 6. Orthogonal projections of magnetization vector end points during progressive alternating field demagnetization treatments for pilot subsamples at every site from Rurutu. Open (solid) symbols show the magnetic vectors projected onto the vertical (horizontal) plane. Numbers adjacent to symbols represent the $A F$ intensity (mT).

small). This mean is adopted as the characteristic direction for this site.

\section{C-site}

Two pilot subsamples were progressively cleaned at the $A F$ levels of $2.5,5,7.5,10$, $12.5,15,20,25,30,40$, and $50 \mathrm{mT}$. After eliminating a scanty VRM at the $A F$ level of 2.5 $\mathrm{mT}$, one component is recognized up to the $A F$ level of $15 \mathrm{mT}$. Above the $20 \mathrm{mT}$ level, the remanent magnetization is relatively weak and unstable (Fig. 6-C02A). The mean direction of the component obtained by the PCA (the range is from 0 to $15 \mathrm{mT}$ or from 2.5 to $30 \mathrm{mT}$ ) is $198.4^{\circ}$ in declination and $43.3^{\circ}$ in inclination for the two pilot subsamples. The mean direction of the residual magnetization after the AFD treatment at $5 \mathrm{mT}$ (ODF) level, is $195.2^{\circ}$ in declination and $42.7^{\circ}$ in inclination, being in good agreement with the mean obtained by the PCA (the angular difference is $2.4^{\circ}$ ). The mean direction of the residual magnetization after the ODF demagnetization is $195.5^{\circ}$ in declination and $54.5^{\circ}$ in inclination ( $k=47.6$ and $\alpha_{95}=9.8^{\circ}$ ) for all six subsamples (Fig. 7-C and Table 1) and is adopted as the characteristic direction for this site.

D-site

Two pilot subsamples were progressively cleaned at the $A F$ levels of $2.5,5,7.5,10$, $12.5,15,20,25,30,40$, and $50 \mathrm{mT}$. After eliminating a scanty VRM at the $A F$ level of 5 $\mathrm{mT}$, similar to the $\mathrm{C}$-site, one component is recognized up to the $A F$ level of $25 \mathrm{mT}$. Above the $30 \mathrm{mT}$ level, the remanent magnetization is relatively weak and does not have the 


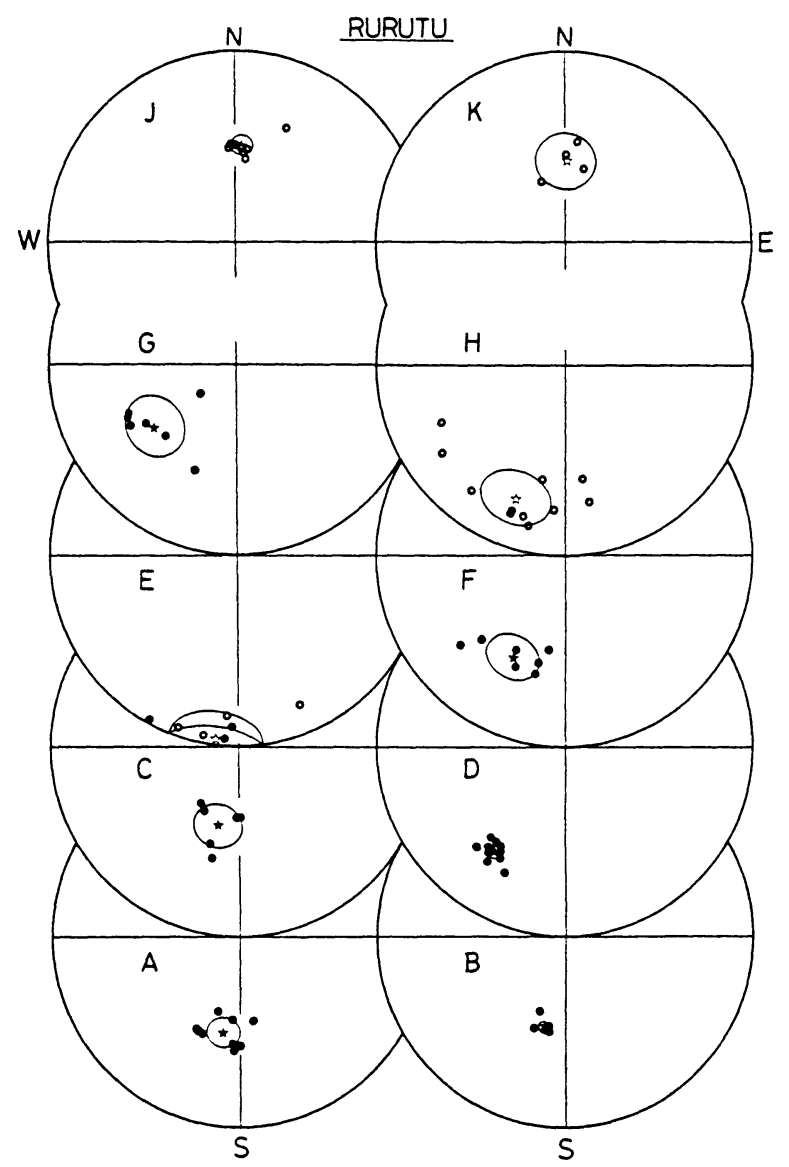

Fig. 7. Directions of magnetization for all demagnetized subsamples of volcanic rocks at every site from Rurutu. The mean direction for each site is indicated by a star with its $95 \%$ confidence interval.

identified direction (Fig. 6-D02A). The mean direction of the component obtained by the PCA (the range is from 0 or $5 \mathrm{mT}$ to $25 \mathrm{mT}$ ) is $218.3^{\circ}$ in declination and $28.1^{\circ}$ in inclination for the two pilot subsamples. The mean direction of the residual magnetization after the AFD treatment at the $15 \mathrm{mT}(\mathrm{ODF})$ level, is $219.0^{\circ}$ in declination and $31.8^{\circ}$ in inclination, being in good agreement with the mean obtained by the PCA (the angular difference is $3.7^{\circ}$ ). The mean direction of the residual magnetization after the ODF demagnetization is $215.0^{\circ}$ in declination and $33.2^{\circ}$ in inclination $\left(k=228.4\right.$ and $\left.\alpha_{95}=3.0^{\circ}\right)$ for all eleven subsamples (Fig. 7-D and Table 1) and is adopted as the characteristic direction for this site.

\section{E-site}

Three pilot subsamples were progressively cleaned at the $A F$ levels of 5, 10, 15, 20, 25, 30,40 , and $50 \mathrm{mT}$. The NRM of the rock samples from this site is the most unstable in Rurutu. The subsamples have only the lower coercivity component up to $20 \mathrm{mT}$ and show 
no significant component above the $A F$ level of $25 \mathrm{mT}$ (Fig. 6-E03A). The mean direction of the component obtained by the PCA (the range is from 0 or $5 \mathrm{mT}$ to $20 \mathrm{mT}$ on average) is $209.4^{\circ}$ in declination and $-3.7^{\circ}$ in inclination for the three pilot subsamples. The mean direction of the lower coercivity component after the AFD treatment at the $15 \mathrm{mT}$ level, is $186.1^{\circ}$ in declination and $-3.6^{\circ}$ in inclination and does not well agree with the mean obtained by the PCA (the angular difference is $23.3^{\circ}$ ). This disagreement may be attributed to inaccurate separation of the components by the PCA due to quick intensity decay against the PAFD treatment. The mean direction of the residual magnetization after the AFD treatment of the $15 \mathrm{mT}$ level is $187.3^{\circ}$ in declination and $-3.9^{\circ}$ in inclination $\left(k=17.7\right.$ and $\left.\alpha_{95}=14.8^{\circ}\right)$ for all seven subsamples (Fig. 7-E and Table 1), although this is not such a good estimate. This mean is adopted as the characteristic direction for this site.

$F$-site

Two pilot subsamples were progressively cleaned at the $A F$ levels of $2.5,5,7.5,10$, $12.5,15,20,25,30,40$, and $50 \mathrm{mT}$. The two pilot subsamples have both lower and higher coercivity components separated at the $A F$ level of $15 \mathrm{mT}$. The directions of these two components are almost the same (Fig. 6-F01A). Only the higher coercivity component can be separated by the PCA (the range is from 10 to $40 \mathrm{mT}$ for F01A or from $25 \mathrm{mT}$ to the origin for the other), and the mean direction of the component is $213.8^{\circ}$ in declination and $42.8^{\circ}$ in inclination for the two pilot subsamples. The mean direction of the residual magnetization after the AFD treatment at the $15 \mathrm{mT}$ (ODF) level is $212.9^{\circ}$ in declination and $39.8^{\circ}$ in inclination, being in good agreement with the mean obtained by the PCA (the angular difference is $3.1^{\circ}$ ). The rest of the subsamples were cleaned at the ODF of $15 \mathrm{mT}$, and the mean direction of the residual magnetization after the ODF demagnetization is $207.6^{\circ}$ in declination and $39.6^{\circ}$ in inclination $\left(k=34.1\right.$ and $\left.\alpha_{95}=10.5^{\circ}\right)$ for all seven subsamples (Fig. 7-F and Table 1). This mean is adopted as the characteristic direction for this site.

\section{G-site}

Three pilot subsamples were progressively cleaned at the $A F$ levels of $5,10,15,20,25$, 30,40 , and $50 \mathrm{mT}$. The NRM of the rock samples from this site is the most unstable in Rurutu, similar to the E-site. After eliminating a scanty VRM at the $A F$ level of $5 \mathrm{mT}$, the subsamples have only lower coercivity components up to $15 \mathrm{mT}$ and show no significant component above the $A F$ level of $20 \mathrm{mT}$ (Fig. 6-G01). The mean direction of the component obtained by the PCA (the range is from 5 to $20 \mathrm{mT}$ for G01 or from $5 \mathrm{mT}$ to the origin for the rest two) is $241.1^{\circ}$ in declination and $40.1^{\circ}$ in inclination for the three pilot subsamples. The mean direction of the lower coercivity component after the AFD treatment at the $15 \mathrm{mT}$ level, is $236.7^{\circ}$ in declination and $41.3^{\circ}$ in inclination and does not significantly differ from the mean obtained by the PCA (the angular difference is $3.5^{\circ}$ ). The mean direction of the residual magnetization after the AFD treatment of the $15 \mathrm{mT}$ level is $233.6^{\circ}$ in declination and $44.3^{\circ}$ in inclination $\left(k=23.8\right.$ and $\left.\alpha_{95}=12.6^{\circ}\right)$ for all seven subsamples (Fig. 6-G and Table 1), although this is not such a good estimate. This mean is adopted as the characteristic direction for this site.

\section{$H$-site}

Three pilot subsamples were progressively cleaned at the $A F$ levels of $5,7.5,10,12.5$, $15,20,25,30,40$, and $50 \mathrm{mT}$. Only one stable component, although this is slightly scattered, is recognized after eliminating a scanty VRM at the $A F$ level of 7.5 or $10 \mathrm{mT}$ for only one pilot subsample (Fig. 6-H01A). The remanent magnetization intensity for two pilot subsamples, H04B and H05A, quickly decays to about one tenth after the AFD of the $5 \mathrm{mT}$ level. Therefore, the component cannot be separated well by the PCA (the range is from 0 or 
$20 \mathrm{mT}$ to the origin) and its directions are different from each other (maximum difference is about $115^{\circ}$ in declination). The mean direction is $248.4^{\circ}$ in declination and $-20.6^{\circ}$ in inclination for the three pilot subsamples. The mean direction of the residual magnetization after the AFD treatment at the $10 \mathrm{mT}$ (ODF) level, is $208.2^{\circ}$ in declination and $-24.5^{\circ}$ in inclination and does not agree with the mean direction obtained by the PCA (the angular difference is $37.5^{\circ}$ ). On account of the poor separation by the PCA, the rest of the subsamples were cleaned at the ODF of $7.5 \mathrm{mT}$, and the mean direction of the residual magnetization of all eleven subsamples after the ODF demagnetization is adopted as the characteristic direction for this site (Fig. 7- $\mathrm{H}$ and Table 1); $200.3^{\circ}$ in declination and $-25.9^{\circ}$ in inclination $\left(k=13.0\right.$ and $\left.\alpha_{95}=13.1^{\circ}\right)$. The rock samples from this site show an ambiguous direction, which can be judged to be neither the normal nor the reversed.

\section{$J$-site}

Four pilot subsamples were progressively cleaned at the $A F$ levels of 5, 10, 15, 20, 25, 30,40 , and $50 \mathrm{mT}$. After eliminating a scanty VRM at the $A F$ level of $5 \mathrm{mT}$, similar to the $\mathrm{C}$ - and D-sites, one component is recognized up to the $A F$ level of $25 \mathrm{mT}$. Above the $30 \mathrm{mT}$ level the remanent magnetization does not have an identified direction (Fig. 6-J04A). The mean direction of the component obtained by the PCA (the range is from 0 or $5 \mathrm{mT}$ to 30 $\mathrm{mT}$ ) is $5.7^{\circ}$ in declination and $-48.7^{\circ}$ in inclination for the four pilot subsamples. The mean direction of the residual magnetization after the AFD treatment at the $15 \mathrm{mT}$ (ODF) level, is $1.1^{\circ}$ in declination and $-48.6^{\circ}$ in inclination and does not significantly differ from the mean obtained by the PCA (the angular difference is $3.1^{\circ}$ ). The mean direction of the residual magnetization after the ODF demagnetization is $3.9^{\circ}$ in declination and $-48.3^{\circ}$ in inclination $\left(k=109.6\right.$ and $\alpha_{95}=4.6^{\circ}$ ) for all ten subsamples (Fig. 7-J and Table 1) and is adopted as the characteristic direction for this site. The samples from this site show the normal direction, similar to the $\mathrm{K}$-site described below.

\section{$K$-site}

Two pilot subsamples were progressively cleaned at the $A F$ levels of $2.5,5,7.5,10$, $12.5,15,20,25,30,40$, and $50 \mathrm{mT}$. One component, although this is slightly scattered, is recognized after eliminating a VRM at the $A F$ level of $10 \mathrm{mT}$. Above the $30 \mathrm{mT}$ level the remanent magnetization does not have an identified direction (Fig. 6-K01A). The mean direction of the component obtained by the PCA (the range is from 10 to $20 \mathrm{mT}$ or from 7.5 to $40 \mathrm{mT}$ ) is $-1.7^{\circ}$ in declination and $-43.6^{\circ}$ in inclination for the two pilot subsamples. The mean direction of the residual magnetization after the AFD treatment at the $20 \mathrm{mT}$ (ODF) level, is $10.7^{\circ}$ in declination and $-52.0^{\circ}$ in inclination and rather differs from the mean direction obtained by the PCA (the angular difference is $12.1^{\circ}$ ). This difference may be attributed to inappropriate selection of the ODF, because the residual magnetization intensity decays to $20-40 \%$ after the AFD treatment at the $20 \mathrm{mT}$ level. The mean direction of the residual magnetization after the AFD treatment at the $20 \mathrm{mT}$ level is $1.6^{\circ}$ in declination and $-55.4^{\circ}$ in inclination $\left(k=55.7\right.$ and $\left.\alpha_{95}=12.4^{\circ}\right)$ for all four subsamples (Fig. 7-K, Table 1), although this is not such a good estimate. This mean is adopted as the characteristic direction for this site.

\section{Discussion and Conclusion}

\subsection{Rarotonga}

The characteristic directions for all sites, except for E-site from Rarotonga, are shown in Fig. 8 (right) and are listed in Table 1. TARLING (1967) has already reported paleomagnetic 


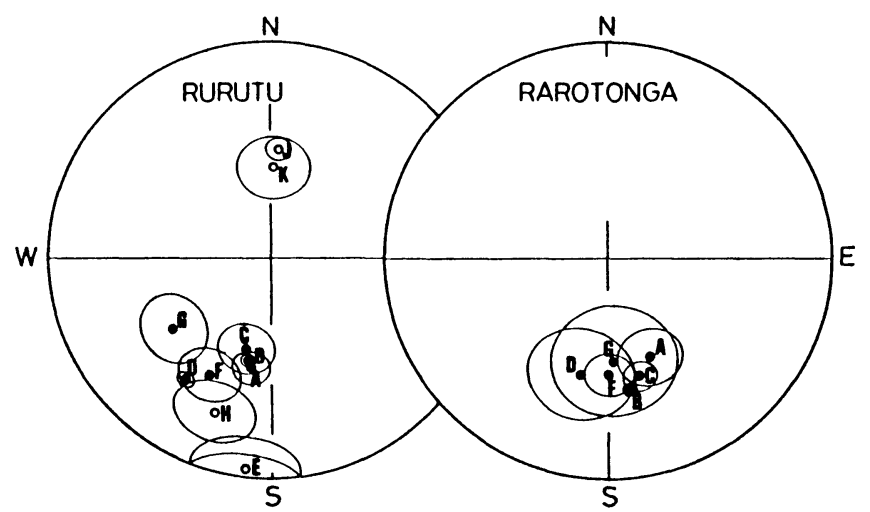

Fig. 8. Mean directions (characteristic directions) for all sites except for E-site from Rarotonga (right) and for all the sites from Rurutu (left) with their $95 \%$ confidence intervals.

directions from Rarotonga. These directions, however, are fairly scattered both within and between sites and are inappropriate to calculate the PSV and to test the "fixed hot spot" hypothesis. His results from Tuoro quarry, the northwestern locality of Rarotonga, show the mean direction of $178.7^{\circ}$ in declination and $47.5^{\circ}$ in inclination $\left(k=21.1\right.$ and $\left.\alpha_{95}=17.1^{\circ}\right)$ for five sites. The direction from the present study in the same locality is $157.3^{\circ}$ in declination and $48.0^{\circ}$ in inclination for A-site, in case of eliminating the poorly reliable result from Gsite. Tarling's results from Avatiu Valley, near the center of this island, show the mean direction of $220.1^{\circ}$ in declination and $59.2^{\circ}$ in inclination $\left(k=3.9\right.$ and $\left.\alpha_{95}=30.0^{\circ}\right)$ for nine sites. The mean from the present study in the same locality is $168.1^{\circ}$ in declination and $41.5^{\circ}$ in inclination for two sites (B and C). Our results from two localities do not largely differ from each other. The results of TARLING (1967), however, differ not only from our results but also between the two localities.

The mean direction for all the sites (14 sites) by TARLING (1967) is $203.9^{\circ}$ in declination and $58.2^{\circ}$ in inclination with poor reliability $\left(k=4.7\right.$ and $\left.\alpha_{95}=22.6^{\circ}\right)$. He stated that the scatter of the mean may be attributed not to the PSV but to collection and measurement errors because of high scattering within the site. In contrast, the mean direction of our results (Table 1) for four sites, except for D-, E- and G-sites which have unreliable directions, is $168.3^{\circ}$ in declination and $44.5^{\circ}$ in inclination $\left(k=114.8\right.$ and $\left.\alpha_{95}=8.6^{\circ}\right)$ and is obviously more reliable than that of TARLING (1967). Our results just give the evidence for Tarling's explanation that the scatter is attributed to collection and measurement errors.

The ages of volcanic rocks in Rarotonga range from 1.1 to $2.3 \mathrm{~m} . \mathrm{y}$. by previous studies and the characteristic directions obtained in the present study are reversed for all sites. These results obviously indicate that the most recent and large-scale volcanism occurred during the Matuyama reversed polarity chron in this island. We measured the geomagnetic total intensity and its daily variation by a portable proton magnetometer at 138 points on Rarotonga at the same time as the rock sampling. We subtracted the daily variation values from the observed intensity values and then calculated the total intensity anomaly on these points from IGRF- 
80 (International Geomagnetic Reference Field) in the laboratory. The anomaly contour, which was drawn using the anomalies at the points, has a pattern of negative and positive values in the north and south, respectively (Fig. 9-left). As we intend to describe the detailed discussion of the model calculation on the other paper, we here show only the schematic model (Fig. 9-b) explaining the observed anomaly pattern roughly. This schematic model also suggests that the rock body forming Rarotonga has reversed magnetization. However, it is impossible to deny the existence of a normally magnetized body in the deeper underground or on a small scale.

On the basis of the $\mathrm{K}-\mathrm{Ar}$ ages and the ${ }^{87} \mathrm{Sr} /{ }^{86} \mathrm{Sr}$ ratios (MATSUDA et al., 1984), it is obvious that Rarotonga does not belong to the volcanic islands which originated from the magma source of a "hot spot" located at MacDonald Seamount. This is reasonable because Rarotonga is situated at a position which deviates from the main linear trending for the CookAustral islands chain. The average migration rate of the Cook-Austral volcanism is predicted to be $10.9 \mathrm{~cm} /$ year from a plate-mantle rotation pole of $70^{\circ} \mathrm{N}$ and $101^{\circ} \mathrm{W}$ with the rate for Hawaiian Islands of $9.7 \mathrm{~cm} /$ year (MCDOUGALL and DUNCAN, 1980). Using this and assuming that there is no relative motion between the islands chain and Rarotonga, it is suggested that the most recent volcanism on Rarotonga occurred near Mangaia, which is situated southeast of Rarotonga (Fig. 1). The K-Ar ages of volcanic rocks from Mangaia, however, range from 13 to 20 m.y. (DALRYMPLE et al., 1975; TURNER and JARRARD, 1982) and do not support the existence of a possible "hot spot".

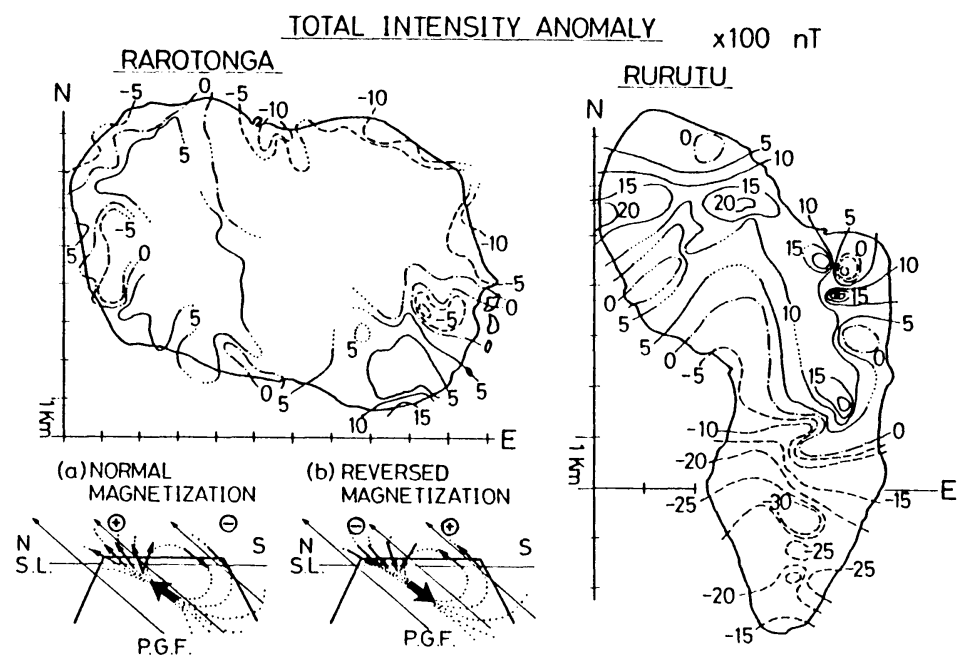

Fig. 9. The geomagnetic total intensity anomaly patterns on Rarotonga (left) and Rurutu (right). The anomalies are calculated from IGRF-80 using the observed intensity at 138 and 123 points on Rarotonga and Rurutu, respectively. Schematic models giving a common anomaly pattern are also shown; (a) anomaly pattern in the case of the normal magnetization body and (b) anomaly pattern in the case of the reversed magnetization body. S.L., sea level; P.G.F., the present geomagnetic field. 
The paleolatitude of Rarotonga, calculated from the mean direction, is $26.6^{\circ} \mathrm{S}$ and shows that Rarotonga should have been situated about $5^{\circ}$ south of the present position. This induces such a high migration rate of this island that the paleolatitude value is not thought to be reasonable. Therefore, the mean direction may include mainly the effect of the PSV in this region at that time.

\subsection{Rurutu}

The characteristic directions for all the sites from Rurutu are shown in Fig. 8 (left) and listed in Table 1. Volcanic rocks from the northeastern part (A, B and K sites) of Rurutu have ages from 7.5 to 11.2 m.y., while those from the western part (E, $\mathrm{G}$ and $\mathrm{H}$ sites) have ages of about or less than $1 \mathrm{~m}$.y. (MATSUDA et al., 1984). On the basis of regional separation of the ages, we assume that the five sites $\mathrm{A}, \mathrm{B}, \mathrm{C}, \mathrm{J}$, and $\mathrm{K}$ are composed of rocks that originated during older volcanism and the other five sites D, E, F, G, and $\mathrm{H}$ are composed of rocks that originated during younger volcanism.

The mean direction for the former site group is $188.1^{\circ}$ in declination and $51.4^{\circ}$ in inclination $\left(k=254.2\right.$ and $\left.\alpha_{95}=4.8^{\circ}\right)$ using transformed data from the normal to the reverse direction for two sites; $\mathrm{J}$ and $\mathrm{K}$ (Table 1). The paleolatitude calculated from the mean is $32.1^{\circ} \mathrm{S}$. The mean direction for three sites (D, F and G) of the latter group is $218.2^{\circ}$ in declination and $39.5^{\circ}$ in inclination $\left(k=49.3\right.$ and $\left.\alpha_{95}=17.7^{\circ}\right)$ (Table 1) and the paleolatitude is $22.4^{\circ} \mathrm{S}$. These paleolatitude values may suggest that older volcanism should have occurred south of the present position and the younger one should have occurred at or near the present position. This evidence shows that the older volcanism occurred at or near MacDonald Seamount and supporting a "hot spot" hypothesis for the Cook-Austral chain, similar to the $\mathrm{K}$-Ar ages and the ${ }^{87} \mathrm{Sr} /{ }^{86} \mathrm{Sr}$ ratios. However, the difference (about $30^{\circ}$ ) between the mean declination values of the older and younger volcanic rocks cannot be explained by a "hot spot" hypothesis. The rotation of Rurutu can be expected from Pacific Plate rotation sense and rate at present and is surely clockwise. This is resulted in clockwise shift of the declination for the older volcanic rocks. The clockwise shift is completely contrary to our results. The declination difference, therefore, may be due to the geomagnetic secular variation, although this is inconsistent with the interpretation for the inclination change. It is obvious also from the K-Ar ages that younger volcanism occurred at or near the present position according to the sea-floor spreading (HESS, 1962).

The characteristic directions for E-site and $\mathrm{H}$-site are generally uncommon. Although the source is insolvable, the following possibilities are expected. The first is that the rock body or neighborhood around these sites has been inclined. If so, the highly clockwise deflected direction for G-site may be attributed to the same cause. The second is the effect of the geomagnetic secular variation. However, the difference of the uncommon direction values from the common one (for example, the direction calculated from the geocentric dipole hypothesis) must be too high to consider the effect. The last is that a volcanism having formed rocks in these sites should have occurred during the geomagnetic field reversal. The Matuyama-Brunhes reversal boundary, Jaramillo subchron boundary or possible excursions can be given as the source.

It is obviously impossible to assume that Rurutu originated from only one volcanism because of the existence of two K-Ar age ranges for the volcanic rocks. On the basis of the geomagnetic total intensity and its daily variation measured by a portable proton magnetometer at 123 points on Rurutu at the same time as the rock sampling, we subtracted the daily variation values from the observed intensity values and then calculated the total 
intensity anomaly at these points from IGRF- 80 in the laboratory. The anomaly contour, which was drawn using the anomalies at the points, generally has a pattern of positive and negative values in the north and south, respectively (Fig. 9-right). As we intend to describe the detailed discussion on the model calculation in the other paper, we here show only the schematic model (Fig. 9-a) explaining the observed anomaly pattern roughly. This anomaly pattern suggests that the major part of the rock body forming Rurutu has the normal magnetization, as explained by this schematic model. However, the distribution of the local anomaly peaks as seen in the northern, northeastern, and southern regions suggests the existence of the reversely magnetized rock bodies. This anomaly pattern is in accordance with the paleomagnetic results showing both the normal and the reversed directions. These results are evidence for the existence of several volcanisms and may deny the "hot spot" hypothesis that only one fixed magma source should take part in the formation of one volcanic chain (exactly, the Cook-Austral chain). Considering also the conclusion for Rarotonga, we had better modify the concept of the "fixed hot spot" hypothesis when applied to the CookAustral chain and discuss the formation of this chain using the concept of "hot line" by BONATTI and HARRISON (1976), as described by TURNER and JARRARD (1982).

We express our special thanks to L. Chungue, Observatoire de Geophysique Pamatai, Centre Orstom de Papeete, Tahiti (French Polynesia), for the preparation of the field work and for invaluable discussions and help during sample collection on Rurutu. This work was supported by the Ministry of Education, Science and Culture Grant-in-Aid for Overseas Scientific Survey No. 404138.

\section{REFERENCES}

Bonatti, E. and C. G. A. HARrison, Hot lines in the Earth's mantle, Nature, 263, 402-404, 1976.

Dalrymple, G. B., R. D. JarRard, and D. A. Clague, K-Ar ages of some volcanic rocks from the Cook and Austral Islands, Geol. Soc. Am. Bull., 86, 1463-1467, 1975.

Duncan, R. A. and W. Compston, Sr-isotope evidence for an old mantle source region for French Polynesia volcanism, Geology, 4, 728-732, 1976.

Duncan, R. A. and I. McDougall, Linear volcanism in French Polynesia, J. Volcanol. Geotherm. Res., 1, 197-227, 1976.

Fisher, R. A., Dispersion on a sphere, Proc. R. Soc., Ser. A., 217, 295-305, 1953.

Hess, H. H., History of Ocean basins, in Petrologic Studies: A Volume to Honor A. F. Buddington, edited by A. E. J. Engel et al., p. 599, Geological Society of America, 1962.

JARRARD, R. D. and D. A. Clague, Implications of Pacific island and seamount ages for the origin of volcanic chains, Rev. Geophys. Space Phys., 15, 57-76, 1977.

Katao, H., H. Morinaga, M. Hyodo, H. Inokuchi, J. Matsuda, and K. Yaskawa, Geomagnetic paleosecular variation and $\mathrm{K}-\mathrm{Ar}$ ages in Hiva-Oa Island, Marquesas, French Polynesia, J. Geomag. Geoelectr., 40, 703-714, 1988.

Kirschvink, J. L., The least-squares line and plane and the analysis of palaeomagnetic data, Geophys. J. R. astr. Soc., 62, 699-718, 1980.

Matsuda, J., K. Notsu, J. OKano, K. Yaskawa, and L. Chungue, Geochemical implications from $\mathrm{Sr}$ isotopes and $\mathrm{K}-\mathrm{Ar}$ age determinations for the Cook-Austral Islands chain, Tectonophysics, 104, 145-154, 1984.

McDougall, I. and R. A. Duncan, Linear volcanic chains-recording plate motions?, Tectonophysics, 63, 275-295, 1980.

Morgan, W. J., Deep mantle convection plumes and plate motions, Am. Assoc. Pet. Geol., 56, 203-213, 1972.

TARling, D. H., Some paleomagnetic results from Rarotonga, Cook Islands, N. Z. J. Geol. Geophys., 10, 1400-1406, 1967. 
TURner, D. L. and R. D. JARRARD, K-Ar dating of the Cook-Austral Island chain: A test of the hot-spot hypothesis, J. Volcanol. Geotherm. Res., 12, 187-220, 1982.

Wilson, J. T., A possible origin of the Hawaiian Islands, Can. J. Phys., 41, 863-870, 1963. 